\title{
Cone Beam Computed Tomography-guided Management of Cervical Perforative Internal Resorption in Permanent Mandibular First Molar
}

\author{
${ }^{1}$ Rasika A Naik, ${ }^{2}$ Manoj M Ramugade, ${ }^{3}$ Nilofar B Attar, ${ }^{4}$ Kishor D Sapkale
}

\begin{abstract}
Internal resorption in the permanent dentition is a rare pathologic condition. Clinical differentiation of perforative cervical internal resorption from cervical external resorption is considered to be a challenging task. Advanced imaging techniques, such as cone beam computed tomography (CBCT) have proven vital diagnostic tools in the detection and management of these lesions. Management of a perforated internal resorption needs comprehensive endorestorative and periodontal approach. This article describes 1 year follow-up of the successfully managed perforative cervical internal resorption in permanent mandibular first molar. The affected tooth was endodontically treated, and the resorptive defect was restored with resin-modified glass ionomer cement (RMGIC) through periodontal flap surgery.
\end{abstract}

Keywords: Cone beam computed tomography, Perforative cervical internal resorption, Permanent mandibular first molar, RMGIC.

How to cite this article: Naik RA, Ramugade MM, Attar NB, Sapkale KD. Cone Beam Computed Tomography-guided Management of Cervical Perforative Internal Resorption in Permanent Mandibular First Molar. Int J Prosthodont Restor Dent 2016;6(3):73-77.

Source of support: Nil

Conflict of interest: None

\section{INTRODUCTION}

Cone beam computed tomography (CBCT) plays an esteemed role in the assessment and management of complex root canal anatomy, dentoalveolar trauma, and tooth resorption. ${ }^{1,2}$ Cone beam computed tomography provides an unparalleled three-dimensional visualization of complex dental anatomy and associated pathology. Literature highlights the potential benefits of CBCT over conventional radiography in the diagnosis and management of resorptive lesions. ${ }^{3,4}$

\footnotetext{
${ }^{1,3}$ Assistant Professor, ${ }^{2,4}$ Associate Professor

1,2,4 Department of Conservative Dentistry and Endodontics Government Dental College and Hospital, Mumbai, Maharashtra India

${ }^{3}$ Department of Periodontology, Government Dental College and Hospital, Mumbai, Maharashtra, India
}

Corresponding Author: Rasika A Naik, Assistant Professor Department of Conservative Dentistry and Endodontics Government Dental College and Hospital, Mumbai, Maharashtra India, Phone: +919833675464, e-mail: rasikanaik11@gmail.com
Internal resorption in permanent dentition is a rare pathologic event with the prevalence of 0.01 to $1 \%{ }^{5}$ Internal resorption is characterized by progressive odontoclastic destruction of dental hard tissues originating from the dental pulp. ${ }^{6}$ Although the exact etiology of resorption is not known, certain predisposing factors like trauma, pulpal inflammation or infection, excessive orthodontic forces, etc. have been described. ${ }^{7}$ Resorptive lesions being asymptomatic are often identified on routine radiographs. Symptoms usually develop only after periodontal perforation and secondary infection. The management of perforated internal resorption requires a multidisciplinary approach involving endorestorative and periodontal intervention. The success of the case depends upon complete debridement of the resorptive tissue and sealing of the defect by surgical or nonsurgical approach. Materials like mineral trioxide aggregate ${ }^{8}$ and resin-modified glass ionomer cement (RMGIC), ${ }^{9}$ have shown promising results in perforation repair. The present case report elaborates on the successful management of cervical perforative internal resorption using CBCT as a diagnostic tool.

\section{CASE REPORT}

A 25-year-old healthy female patient presented with a complaint of pain on chewing in tooth \#36, since 15 days. Clinical examination revealed a prominent pinkish hue in the cervical third of the buccal surface of \#36 with subgingival cavitation defect. Subjacent periodontal tissues appeared healthy (Fig. 1A). The tooth was tender on percussion. Clinical examination was suggestive of resorptive defect in relation to \#36.

An intraoral periapical radiograph of tooth \#36 (Fig. 1B) revealed a well-defined radiolucency in cervical third of the crown \#36 extending mesiodistally from the pulp chamber up to the alveolar crest. Widening of periodontal ligament space without interdental bone loss was evident. Cone beam computed tomography scan of field of view of $16 \times 9 \mathrm{~cm}$ and isotropic resolution provided assessment of the lesion in coronal, axial, and sagittal sections (Figs 2A to C), which revealed hypodense radiolucency ballooning out from pulp chamber and perforating buccally in cervical third of the crown having 

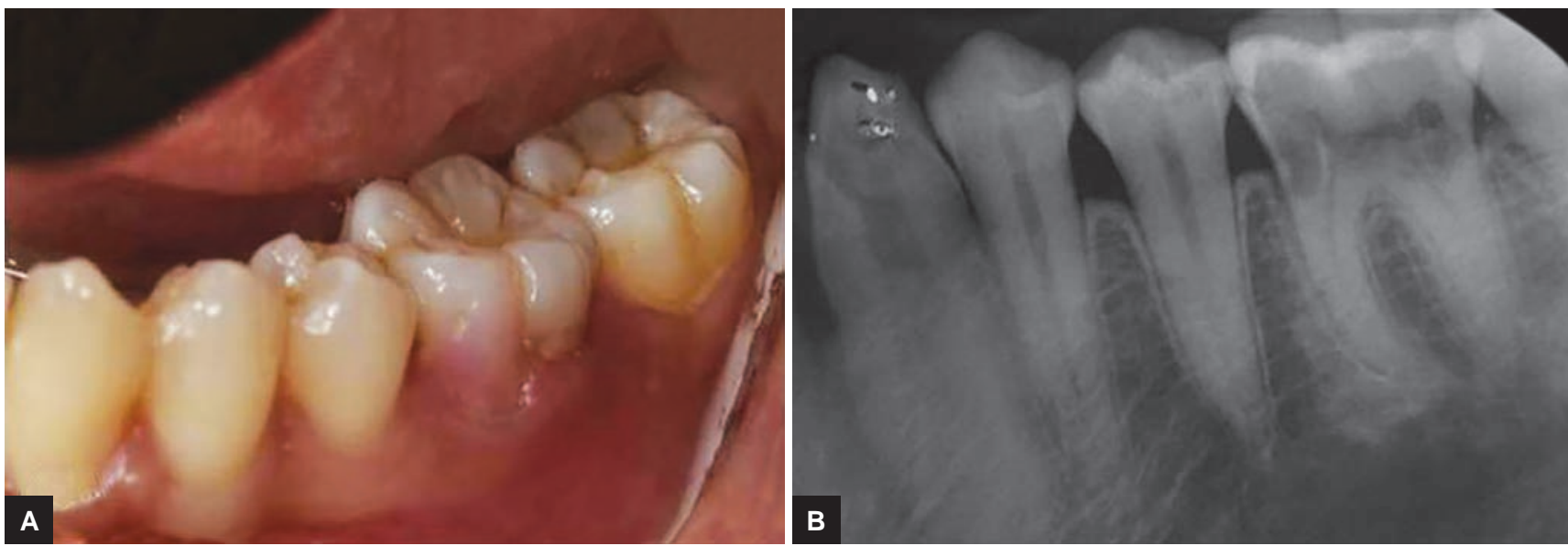

Figs 1A and B: (A) Preoperative intraoral photograph of tooth \#36 exhibiting pinkish hue with cervical cavitation on buccal surface; and (B) preoperative intraoral periapical radiograph of tooth \#36

smooth and well-defined margins. The broader base of the lesion was toward pulp chamber, suggestive of initiation of resorption from pulp chamber, confirming diagnosis of perforated internal resorption. Treatment plan consisted of endodontic treatment of \#36 followed by sealing of perforative defect. Subgingival extent of the defect demanded surgical approach to restore the resorptive defect. Informed consent of patient was taken.
In the first phase, endodontic treatment was initiated following standard protocol under surgical operating microscope (Carl Zeis OPMI PICO; 8× magnification). Perforated resorptive defect was visualized in buccal surface in cervical one-third crown filled with resorptive tissue (Figs $3 \mathrm{~A}$ and $\mathrm{B}$ ). Root canal system was prepared along with copious irrigation of $2.5 \%$ $\mathrm{NaOCl}$. Nonsettable calcium hydroxide paste was used
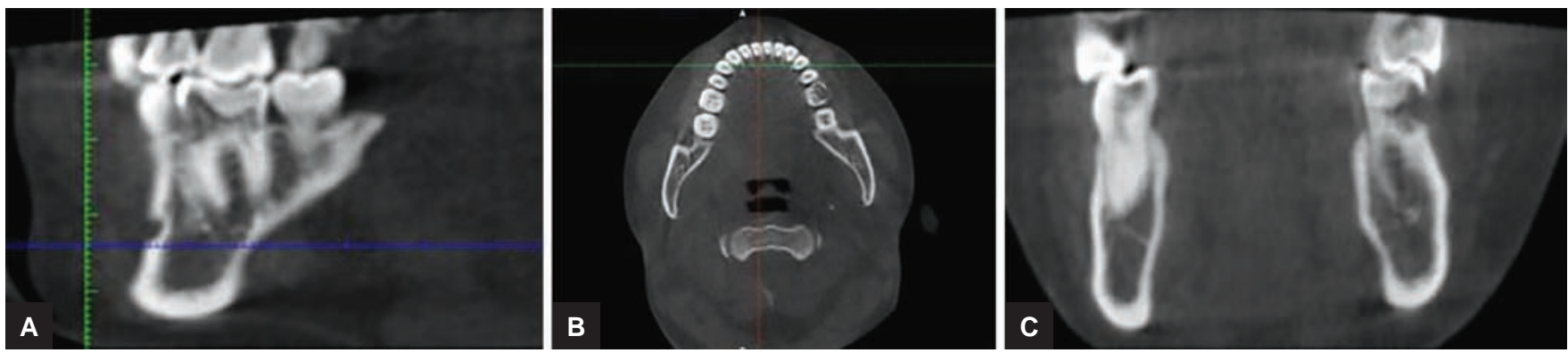

Figs 2A to C: Cone beam computed tomography images: (A) Vertical slice indicating mesiocervical resorption of tooth \#36;

(B) horizontal section at cervical one-third of mandibular arch; and (C) transverse section of tooth \#36 indicating cervical resorption
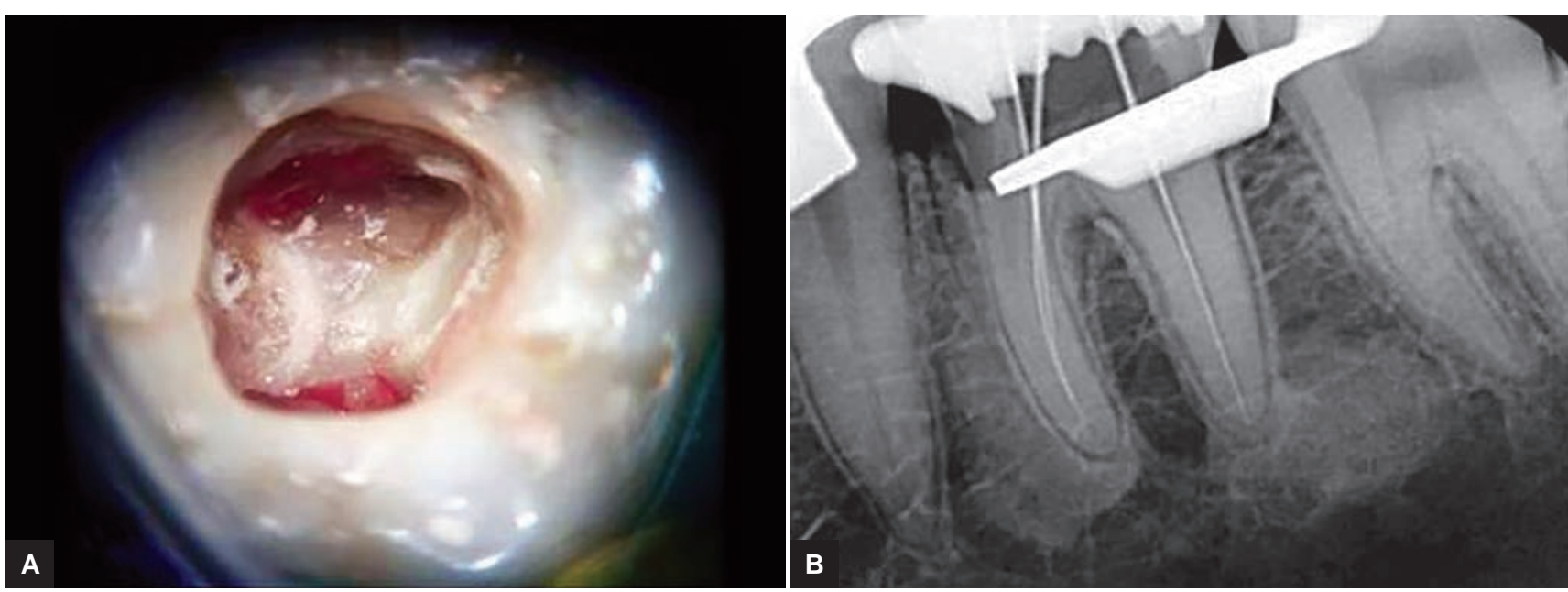

Figs $3 A$ and $B:(A)$ Clinical photograph of pulp chamber of tooth \#36 after access cavity preparation (8× magnification); and $(\mathrm{B})$ radiographic working length determination of tooth \#36 
as an intracanal medicament (Well-Paste ${ }^{\mathrm{TM}}$; Vericom) for 1 week.

Second phase of the treatment involved sealing of the defect after periodontal flap reflection. Full-thickness periodontal flap was reflected in \#34-37 tooth regions under local anesthesia. The resorptive defect was explored to ensure complete debridement of resorptive tissue. The defect was restored with RMGIC (Fuji II, GC Corporation, Tokyo, Japan) (Figs 4A and B), and the flap was then repositioned with suture. After 7 days of satisfactory healing, endodontic treatment in tooth \#36 was completed (Fig. 5A). Tooth was restored with LuxaCore ${ }^{\circledR}$ Dual core buildup composite (DMG, USA) (Figs 5B and C), and full coverage crown was given. Patient was recalled after every 3 months. After 12 months of recall, the tooth \#36 was found to be clinically asymptomatic with no evidence of periodontal and periapical pathology (Fig. 6A). Intraoral periapical radiograph showed healthy periodontal ligament space without any evidence of further tooth resorption (Fig. 6B).
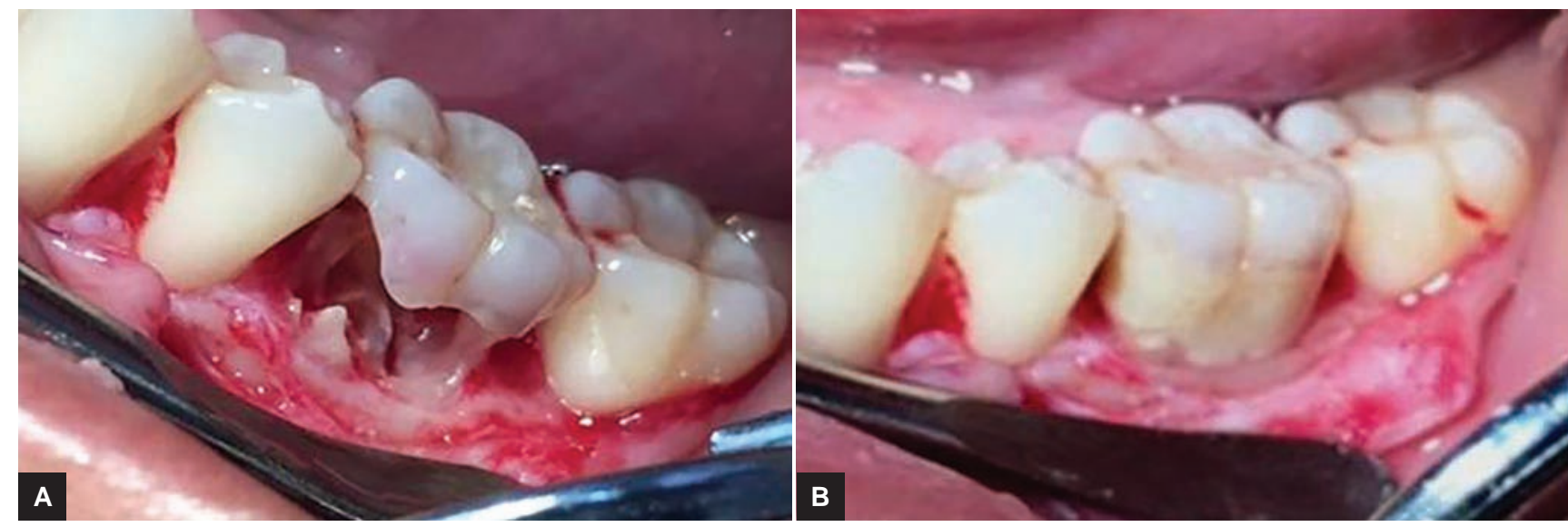

Figs 4A and B: (A) Intraoral photograph after periodontal flap reflection and removal of granulation tissue in tooth \#36; and (B) clinical photograph of tooth \#36 after restoration of defect with RMGIC
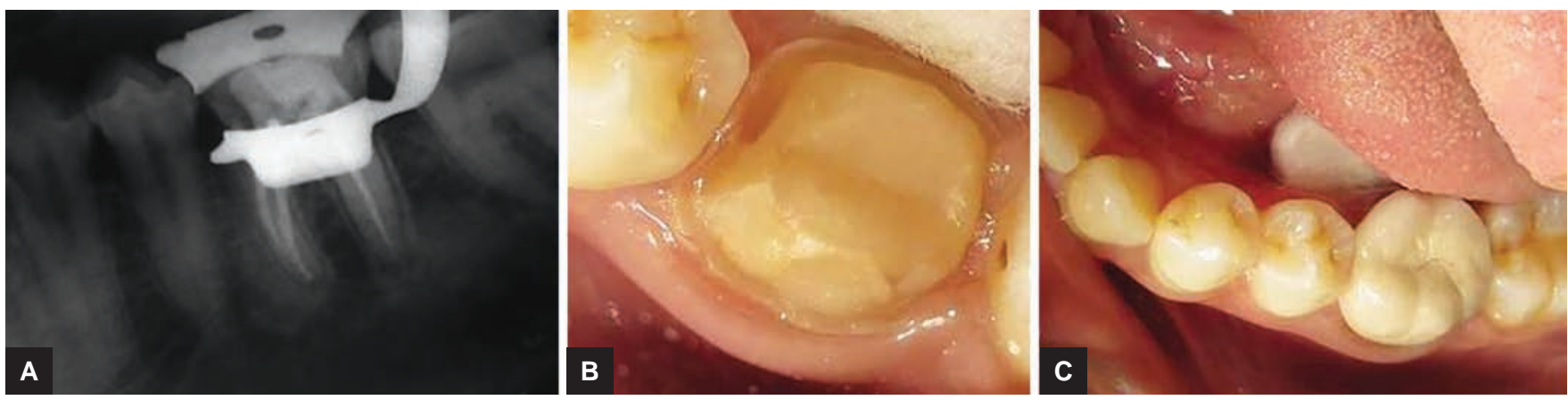

Figs 5A to C: (A) Intraoral periapical radiograph after obturation in tooth \#36; (B) crown preparation after core buildup with LuxaCore; and (C) clinical photograph of tooth \#36 region after 3 months follow-up
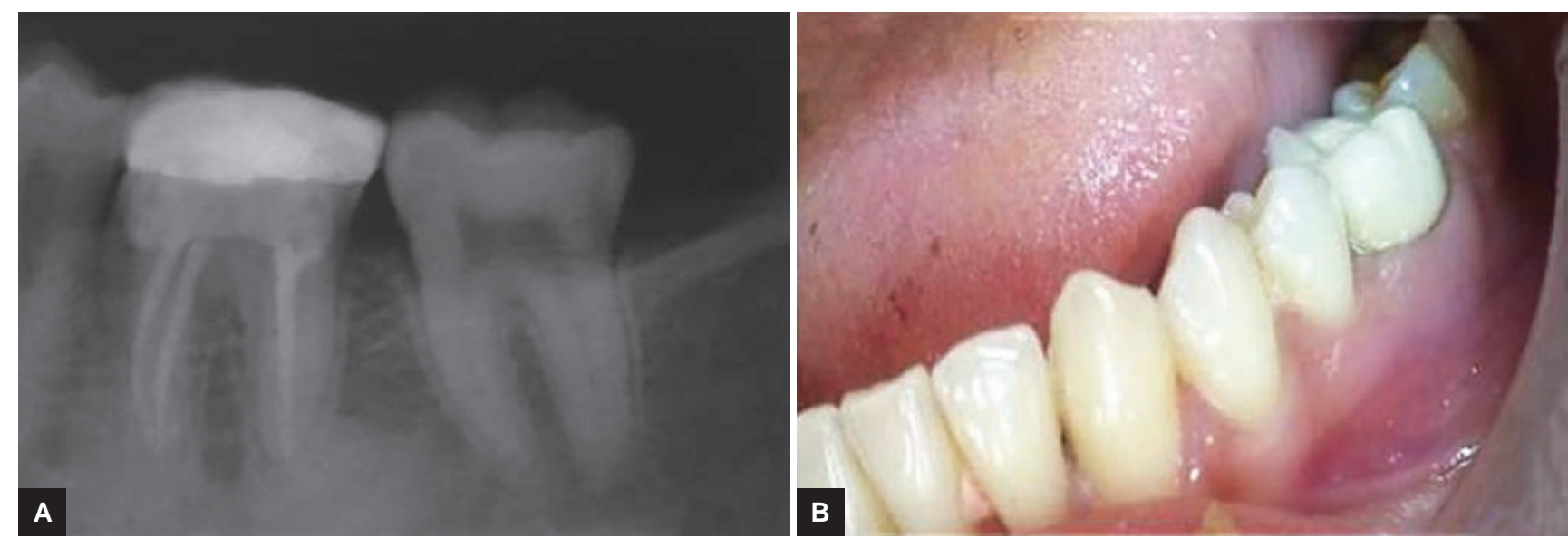

Figs 6A and B: (A) One-year follow-up clinical photograph of tooth \#36; and (B) one-year follow-up intraoral periapical radiograph of tooth \#36 


\section{DISCUSSION}

Internal resorption is a rare, insidious condition, which initiates from dental pulp and destroys the surrounding dental hard tissues. Resorptive cells are odontoclastic in origin. Exposure of predentin due to damaged odontoblastic layer and bacterial stimulation plays an important role in initiation and progression of internal resorption. ${ }^{6}$ Trauma, pulpitis, pulpotomy, tooth transplantation, restorative procedures, orthodontic treatment, etc. are suggested as predisposing factors for internal resorption. ${ }^{5}$ However, none of these factors were identified in the present case.

Clinical differentiation of internal and external cervical resorption is a challenging venture. ${ }^{4}$ These lesions cannot be differentiated only on the basis of a pinkish hue of resorptive defect, which is referred to as "pink tooth of Mummery." 10,11 Cone beam computed tomography being a three-dimensional imaging modality is recommended for differentiation of external and internal resorptive defects. ${ }^{12,13}$ In the present case, CBCT aided diagnosis and assessment of location and extent of lesion preoperatively.

The pathologic communication of root canal system with periodontal apparatus compromises health and viability of tooth and periradicular tissues. ${ }^{5}$ Cervical perforation due to proximity with the crestal bone and epithelial attachment is susceptible to apical epithelial migration and periodontal pocket formation. ${ }^{14}$ Complete debridement of the resorptive tissue from the root canal system and sealing of the perforative defect are key factors for the successful management of perforated internal resorption.

Irregular confines of the resorptive cavity and profuse bleeding created hurdles in resorptive tissue debridement. A total of $2.5 \%$ sodium hypochlorite was used as an irrigant due to excellent tissue-dissolving property. The use of calcium hydroxide as an intracanal medicament was aimed at dissolving remaining resorptive tissue, alkalinizing the environment and arresting further resorption in the short term. ${ }^{15}$

Sealing of the perforative defect was aimed at preventing contamination and to ensure integrity of the periodontal tissues. Mineral trioxide aggregate is the material of choice for repair of subosseous perforations due to its sealing ability and biocompatibility. ${ }^{8}$ In the present case of crestal perforation repair, RMGIC was selected on account of its insolubility in oral fluids, possible tooth reinforcement due to bonding, dual cure capabilities, biocompatibility, and better periodontal tissue response. ${ }^{16,17}$

Endodontic treatment and surgical perforation repair involved comprehensive implementation of endodontic, periodontal, and restorative knowledge and skills and provided a predictable and successful alternative to extraction of the involved tooth.

\section{CONCLUSION}

Early detection and a critical differential diagnosis play a vital role in the management of internal resorption. The use of CBCT is indisputable in the management of the case. Endodontic treatment and surgical perforation repair provided a successful treatment outcome in cervical perforative internal resorption.

\section{ACKNOWLEDGMENT}

Authors would like to thank Dr Mansing G Pawar, Professor and Head, Department of Conservative Dentistry and Endodontics; Dean, GDC \& H Mumbai for his valuable support.

\section{REFERENCES}

1. Cotton TP, Geisler TM, Holden DT, Schwartz SA, Schindler WG. Endodontic applications of cone-beam volumetric tomography. J Endod 2007 Sep;33(9):1121-1132.

2. Tyndall DA, Rathore S. Cone-beam CT diagnostic applications: caries, periodontal bone assessment, and endodontic applications. Dent Clin North Am 2008 Oct;52(4):825-841.

3. Patel S, Dawood A, Wilson R, Horner K, Mannocci F. The detection and management of root resorption lesions using intraoral radiography and cone beam computed tomography: an in vivo investigation. Int Endod J 2009 Sep;42(9): 831-838.

4. Kamburoglu K, Kursun S, Yuksel S, Oztaş B. Observer ability to detect ex vivo simulated internal or external cervical root resorption. J Endod 2011 Feb;37(2):168-175.

5. Haapasalo M, Endal U. Internal inflammatory root resorption: the unknown resorption of the tooth. Endod Topics 2006;14: 60-79.

6. Patel S, Ricucci D, Durak C, Tay F. Internal root resorption: a review. J Endod 2010 Jul;36(7):1107-1121.

7. Andreasen JO, Andreasen FM. Root resorption following traumatic dental injuries. Proc Finn Dent Soc 1992;88 Suppl 1: 95-114.

8. Main C, Mirzayan N, Shabahang S, Torabinejad M. Repair of root perforations using mineral trioxide aggregate: a longterm study. J Endod 2004 Feb;30(2):80-84.

9. Kim SY, Yang SE. Surgical repair of external inflammatory root resorption with resin-modified glass ionomer cement. Oral Surg Oral Med Oral Pathol Oral Radiol Endodontol 2011 Apr;111(4):e33-e36.

10. Patel S, Kanagasingham S. External cervical resorption: a review. J Endod 2009;35:616-625.

11. Gulabivala K, Searson LJ. Clinical diagnosis of internal resorption: an exception to the rule. Int Endod J 1995 Sep;28(5): 255-260.

12. Estrela C, Bueno MR, De Alencar AH, Mattar R, Valladares Neto J, Azevedo BC, De Araújo Estrela CR. Method to evaluate 
inflammatory root resorption by using cone beam computed tomography. J Endod 2009 Nov;35(11):1491-1497.

13. Durack C, Patel S. Diagnostic accuracy of small volume cone beam computed tomography and intraoral periapical radiography for the detection of simulated external inflammatory root resorption Int Endod J 2011 Feb;44(2): 136-147.

14. Tsesis I, Fuss Z. Diagnosis and treatment of accidental root perforations. Endod Topics 2006;13:95-107.
15. Türkün M, Cengiz T. The effects of sodium hypochlorite and calcium hydroxide on tissue dissolution and root canal cleanliness: Int Endod J 1997 Sep;30(5):335-342.

16. Martins TM, Bosco AF. Tissue response to coverage of root cavities restored with resin materials: a histomorphometric study in dogs. J Periodontol 2007 Jun;78(6):1075-1082.

17. Al-Sabek F, Shostad S, Kirkwood KL. Preferential attachment of human gingival fibroblasts to the resin ionomer Geristore. J Endod 2005 Mar;31(3):205-208. 
